Note

\title{
Performance and radial distribution profiles of a variable flow rate sprinkler developed for precision irrigation
}

\author{
Robson André Armindo ${ }^{1 *}$, Tarlei Arriel Botrel ${ }^{2}$
}

1UFPR - Depto. Solos e Engenharia Agrícola, R. dos Funcionários, 1540 - 80035-050 -

Curitiba, PR - Brasil.

2USP/ESALQ - Depto. Engenharia de Biossistemas, C.P. 9 - 13418-900 - Piracicaba, SP - Brasil.

*Corresponding author <rarmindo@ufpr.br>

Edited by: José Euclides Stipp Paterniani

Received March 31, 2011

Accepted November 08, 2011

\begin{abstract}
Variable rate sprinklers (VRS) have been developed to promote localized water application of irrigated areas. In Precision Irrigation, VRS permits better control of flow adjustment and, at the same time, provides satisfactory radial distribution profiles for various pressures and flow rates are really necessary. The objective of this work was to evaluate the performance and radial distribution profiles of a developed VRS which varies the nozzle cross sectional area by moving a pin in or out using a stepper motor. Field tests were performed under different conditions of service pressure, rotation angles imposed on the pin and flow rate which resulted in maximal water throw radiuses ranging from 7.30 to $10.38 \mathrm{~m}$. In the experiments in which the service pressure remained constant, the maximal throw radius varied from 7.96 to 8.91 $\mathrm{m}$. Averages were used of repetitions performed under conditions without wind or with winds less than $1.3 \mathrm{~m} \mathrm{~s}^{-1}$. The VRS with the four stream deflector resulted in greater water application throw radius compared to the six stream deflector. However, the six stream deflector had greater precipitation intensities, as well as better distribution. Thus, selection of the deflector to be utilized should be based on project requirements, respecting the difference in the obtained results. With a small opening of the nozzle, the VRS produced small water droplets that visually presented applicability for foliar chemigation. Regarding the comparison between the estimated and observed flow rates, the stepper motor produced excellent results.

Keywords: scheduling irrigation, central pivot, linear irrigation system, automation
\end{abstract}

\section{Introduction}

Variable rate sprinklers (VRS) for mechanical selfpropelled irrigation systems have been developed to promote localized water application in function of the spatio-temporal variability of irrigated areas in Precision Irrigation. Some existing techniques for controlling water application depths include pulse modulation, air injection and controlled movement of a concentric pin, all being activated by solenoid valves. Packages of fabricated pre-calibrated sprinklers can be used as an option for management of site-specific precision irrigation.

Since the 1990's, precision irrigation is being developed in response to the need to provide water to the soil in accordance with spatial variability of field topography, soil type, availability of water to the soil, production system and other factors, with the intent of optimizing production while conserving hydraulic resources and the environment (Stone et al., 2006). Although this is a new area of study, the variable flow irrigation systems should be more efficient in terms of operability and utilization of water and energy (Dukes and Perry, 2006).

King et al. (2005) field tested 32 developed sprinkler prototypes in three points of a linear irrigation system, monitoring water application uniformity which exceeded $90 \%$. Moreover, the reduction in water application uniformity had a minimal effect, utilizing 4 $\%$ of nitrogen in the application. Duke and Perry (2006) evaluated a commercial system and did not observe dif- ferences between the qualities of application in each operating condition. Al-Kufaishi et al. (2006) analyzed the operation of two variable rate sprinklers in precision irrigation and found that the pulse with modulation system was more efficient than the bimodal sequential system, and that during all the tests the pressure of $150 \mathrm{kPa}$ was that which presented the best results. Young et al. (2009) evaluated the Christiansen uniformity coefficient (CUc) of a variable rate sprinkler operated by a pulsing technique controlled by solenoids in a linear irrigation system. The authors reported uniformity values of 94.0, $94.8,91.7$ and $79.5 \%$ for the applied irrigation depths of $25,18,13$ and $6 \mathrm{~mm}$, respectively.

In search of a VRS which permits better control of flow adjustment and at the same time, provides satisfactory radial distribution profiles for various pressures and flow rates, Armindo et al. (2010) developed an automated prototype controlled by a stepper motor and presented its complete construction and hydraulic characteristics. Therefore, the objective of this study was to evaluate the performance and radial distribution profiles of the prototype developed by Armindo et al. (2010) under field conditions.

\section{Materials and Methods}

Project elaboration and ideological conception of the VRS were in Piracicaba, São Paulo state, Brazil. Assembly of the VRS prototype in the field was realized to determine its radial distribution profile. 
The VRS was assembled using equipment of simple construction associated with considerable performance. This included use of the following items: a Y-connector with diameter of $0.025 \mathrm{~m}$, fitting and nipple with diameters of $0.01874 \mathrm{~m}$, PVC pipe, two guide sockets, a pointed pin with angle of attack of $41.58^{\circ}$ constructed of nylon and thread pitch of $0.0009 \mathrm{~m}$, and a conical nipple with diameter of $0.010 \mathrm{~m}$ also made of nylon (Figure 1). In the developed prototype, the movement of the pin, controlled by a stepper motor, occurs in an axial and circular form generally acknowledged as a simple movement of a screw. A deflector support was constructed from PVC in order to adjust the distance between the point of the pin and the center of the deflector. On this support two deflectors were tested, one of four and another of six jets, and both rotary, in search of a satisfactory radial profile.

From the service pressure, nozzle area and coefficient of discharge, the flow of a conventional sprinkler can be calculated using Equation (1).
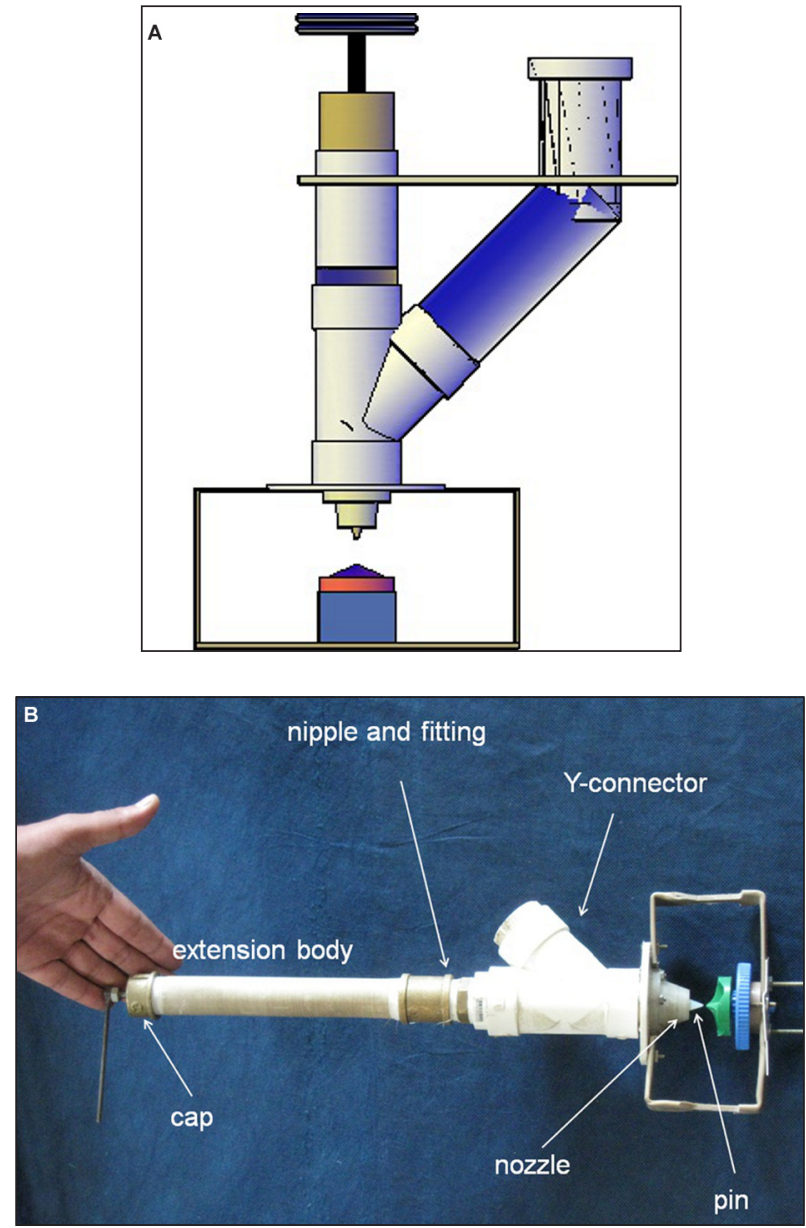

Figure 1 - Image of the constructed prototype. a) Frontal view. Image of the variable rate sprinkler (VRS) prototype. b) Detail in perspective. Image of the pointed pin and nozzle, both made of acrylic. $\mathrm{q}=\mathrm{cd} \cdot \mathrm{S} \cdot \sqrt{2 \mathrm{gH}}$

where: q: flow - $\mathrm{m}^{3} \mathrm{~s}^{-1}$; cd: coefficient of discharge - dimensionless; S: nozzle area $-\mathrm{m}^{2} ; \mathrm{H}$ : service pressure - mwc.

However, in the evaluated VRS, vertical movement of the pin promoted an alteration in the area of the nozzle in function of each angle of rotation, for which Eq. (1) was modified to give Eq. (2) (Armindo et al., 2010) as follows,

$q=\operatorname{cd} \cdot \pi\left\{r^{2}-\left[r-\left(\frac{\varphi \cdot L}{360}\right) \cdot \tan \left(20,79^{\circ}\right)\right]^{2}\right\} \sqrt{2 g H}$

where: L: thread pitch - $\mathrm{m}$; $\mathrm{r}$ : nozzle radius - $\mathrm{m} ; \varphi$ : angle of rotation imposed on the pin - degrees.

Isolating the variable $\varphi$, Eq. (3) was derived which determines the angle of rotation necessary for the VRS to provide the desired flow.

$\varphi=\left[\frac{\left.r-\sqrt{r^{2}-\left(\frac{q}{c d} \cdot \pi \sqrt{2 \mathrm{gH}}\right.}\right)}{L \cdot \tan \left(20,79^{\circ}\right)}\right] \times 360$

The VRS was mounted in a pasture to perform the tests for determination of the radial distribution profile under various operational conditions. Both mounting and the procedure for evaluation of the tests respected the requirements presented by the Procedure for Sprinkler Testing and Performance, found in the norms of the American Society of Agricultural and Biological Engineers (ASABE).

The constructed prototype was installed in a central position with collectors distributed in a scheme of four lines, spaced at $0.50 \mathrm{~m}$ (Figure 2). All collectors utilized in the tests are identical and are the same as those used in the tests performed for evaluation of sprinkler

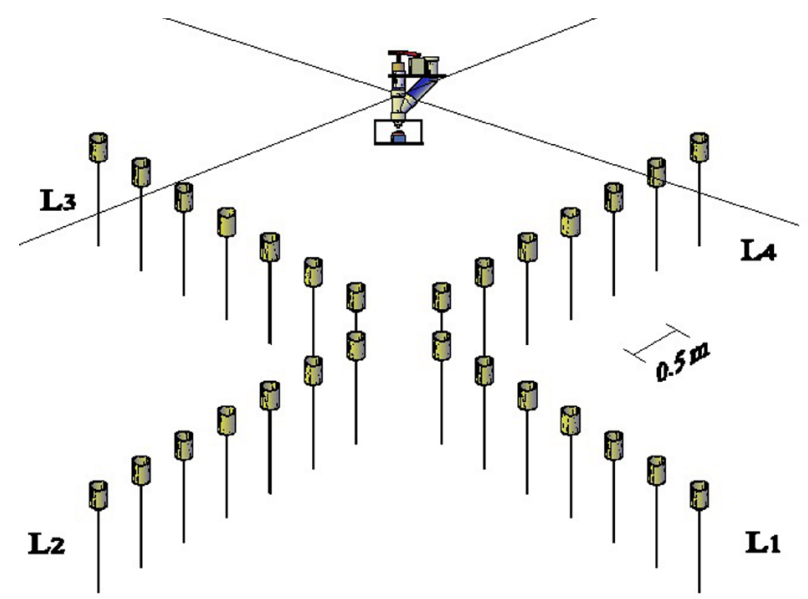

Figure 2 - Distribution of the lines of collectors to be utilized when performing the tests. 

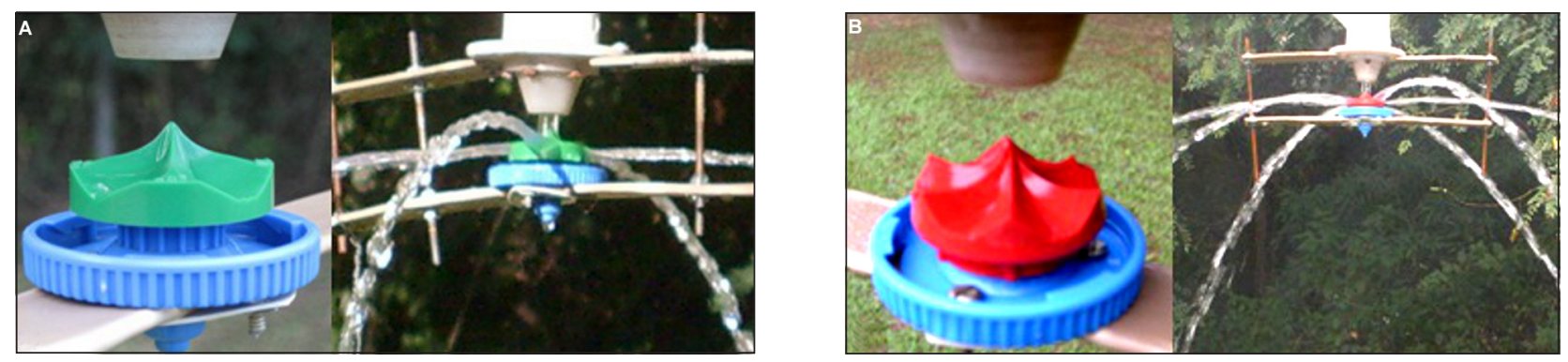

Figure 3 - Images of the rotary reflectors utilized in the field tests. a) four jet deflector. b) six jet deflector.

systems. For evaluation of the water distribution profile two types of rotary deflectors were utilized: i) green deflector which possesses four water jet outlets; and ii) red deflector which possesses six water jet outlets (Figure 3). These deflectors utilized are conventional sprinklers from a commercial manufacturer.

Each experimental period included $1 \mathrm{~h}$ of monitoring, for which the dates and times of irrigation were recorded, as well as the values of wind speed and direction, working water pressure, flow rate and deflector rotation. The data referring to each device tested are based on three repetitions resulting in four average distribution profiles. From there, the average radial distribution profile was determined using the average of the four generated average profiles. The experimental tests were performed using five working water pressures and five angles of rotation imposed on the pin, which resulted in five flow rates (Table 1).The maximum flow rate reached when the VRS is fully open is $1.3889 \mathrm{dm}^{3} \mathrm{~s}^{-1}$.

To eveluate performance of the VRS operating at low, medium and high flow rates, with a single pressure, it was randomly chosen to perform the new field tests using a pressure of $140 \mathrm{kPa}$. Three angles of rotation were imposed on the pin resulting in three flow rates, respectively (Table 2). Tests were conducted while respecting the same requirements followed in the previous experiments, maintaining the same form of analysis of the desired results.

The maximal throw radius referring to each profile was calculated based on the criteria of the ASABE technique which established that throw should be measured from the central sprinkler tested to the collector which received a precipitation intensity of at least $0.26 \mathrm{~mm} \mathrm{~h}^{-1}$. Therefore, the mean profile is calculated based on the four lines $\mathrm{L}_{1}, \mathrm{~L}_{2}, \mathrm{~L}_{3}$ and $\mathrm{L}_{4}$, adjusting polynomials which relate the precipitations of the last four collectors and the reach referring to each collector.

\section{Results and Discussion}

With the exception of the results obtained with the working pressure of $70 \mathrm{kPa}$, the radial profiles presented similar precipitation profiles despite the differences in magnitude (Figure 4). For each desired irrigation application, the position of the pin in the VRS was altered
Table 1 - Flow rates tested in the field to obtain the radial distribution profiles of the variable rate sprinkler as a function of pressure (q) and pin angle of rotation $(\varphi)$.

\begin{tabular}{ccccccc}
\hline & $\begin{array}{c}\mathrm{H} \\
\mathrm{kPa}\end{array}$ & 70 & 105 & 140 & 210 & 280 \\
\cline { 2 - 7 } & \multicolumn{6}{c}{$\begin{array}{c}\mathrm{q} \\
\mathrm{dm}^{3} \mathrm{~s}^{-1}\end{array}$} \\
\hline \multirow{4}{*}{$\varphi$} & 2880 & 0.61666 & & & & \\
degrees & 2520 & & 0.70833 & & & \\
& 3600 & & & 0.94444 & & \\
& 3240 & & & & 1.1027 & \\
& 3960 & & & & & 1.3888 \\
\hline
\end{tabular}

Table 2 - Flow rates (q) tested in the field to obtain the radial distribution profiles of the variable rate sprinkler as a function of the pin angle of rotation $(\varphi)$ for pressure of $140 \mathrm{kPa}$.

\begin{tabular}{cc}
$\varphi$ & $\mathrm{q}$ \\
degrees & $\mathrm{dm}^{3} \mathrm{~s}^{-1}$ \\
720 & 0.61666 \\
1800 & 0.70833 \\
3600 & 0.94444 \\
\hline
\end{tabular}

resulting in a change in flow and thus a modified throw radius. It is important that the irrigator has knowledge of this information which should be provided by a future manufacturer.

The coefficients of variation $(\mathrm{CV})$, referring to the last collectors of each line $\left(\mathrm{L}_{1}, \mathrm{~L}_{2}, \mathrm{~L}_{3}\right.$ and $\left.\mathrm{L}_{4}\right)$ and utilizing the four jet rotary deflector, are large since in these there is a high variability in the volume collected (Table 3). Therefore, these values were not significant in the regression of polynomials adjusted for calculation of maximal throw (Table 5) established for each experimental condition, even while knowing that each average precipitation intensity (PI), corresponding to each collector, was the result of a factorial of three repetitions and four lines, i.e., the average of 12 replications. The radial distribution profiles obtained with different pressures, angles of rotation imposed on the pin and six jet deflector can be seen below in Figure 5.

The $\mathrm{CV}$ referring to the last collectors of the lines $\left(\mathrm{L}_{1}, \mathrm{~L}_{2}, \mathrm{~L}_{3}\right.$ and $\left.\mathrm{L}_{4}\right)$ when using the six jet rotary deflector, also presented high values for the same reasons 

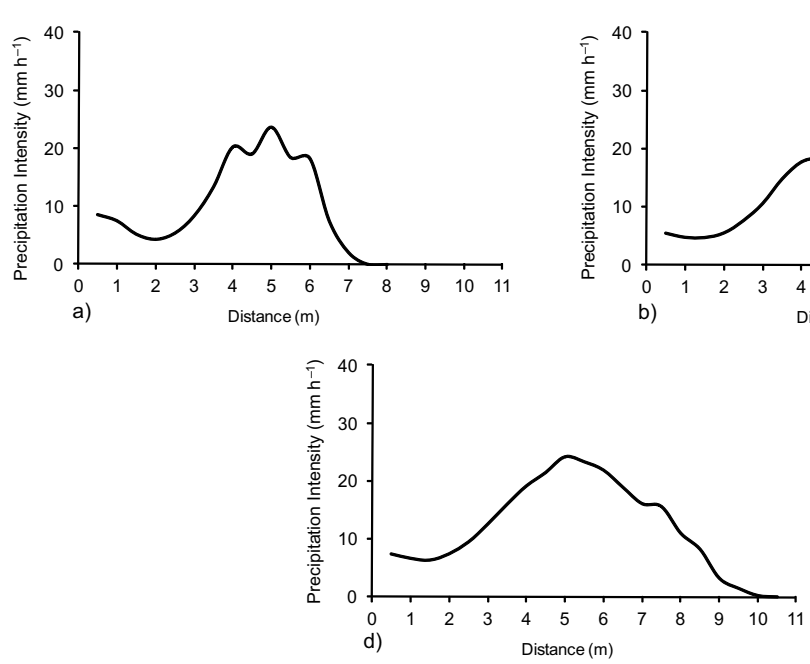
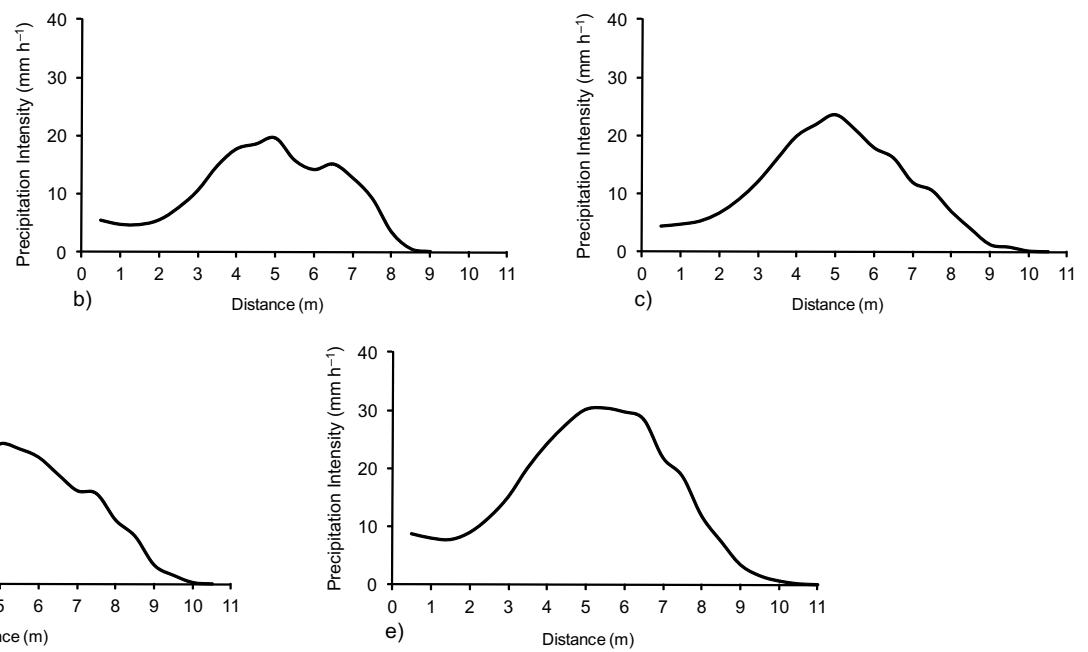

Figure 4 - Average distribution profiles of the variable rate sprinkler operating with different pressures and flow rates and with four jets green rotary reflector. a) $\mathrm{q}=0.6166 \mathrm{dm}^{3} \mathrm{~s}^{-1}, \mathrm{H}=70 \mathrm{kPa}$; b) $\mathrm{q}=0.7083 \mathrm{dm}^{3} \mathrm{~s}^{-1}, \mathrm{H}=105 \mathrm{kPa}$; c) $\mathrm{q}=0.9722 \mathrm{dm}^{3} \mathrm{~s}^{-1}, \mathrm{H}=140 \mathrm{kPa}$;) $\mathrm{q}=1.1667$, $\mathrm{H}=210 \mathrm{kPa}$; e) $\mathrm{q}=1.3889 \mathrm{dm}^{3} \mathrm{~s}^{-1}, \mathrm{H}=200 \mathrm{kPa}$.

Table 3 - Average precipitation intensities (PI) and their respective coefficients of variation (CV) for the flows tested in the field using the four jet green rotary deflector.

\begin{tabular}{|c|c|c|c|c|c|c|c|c|c|c|}
\hline \multicolumn{11}{|c|}{ four jets } \\
\hline$\underset{\mathrm{kPa}}{\mathrm{H}}$ & \multicolumn{2}{|c|}{70} & \multicolumn{2}{|c|}{105} & \multicolumn{2}{|c|}{140} & \multicolumn{2}{|c|}{210} & \multicolumn{2}{|c|}{280} \\
\hline $\begin{array}{c}\mathrm{q}_{\mathrm{obs}} \\
\mathrm{dm}^{3} \mathrm{~s}^{-1}\end{array}$ & \multicolumn{2}{|c|}{0.6166} & \multicolumn{2}{|c|}{0.7083} & \multicolumn{2}{|c|}{0.9722} & \multicolumn{2}{|c|}{1.1667} & \multicolumn{2}{|c|}{1.3889} \\
\hline Distance & $\mathrm{PI}$ & CV & $\mathrm{PI}$ & CV & $\mathrm{PI}$ & CV & $\mathrm{PI}$ & CV & $\mathrm{PI}$ & $\mathrm{CV}$ \\
\hline $\mathrm{m}$ & $\mathrm{mm} \mathrm{h}^{-1}$ & $\%$ & $\mathrm{~mm} \mathrm{~h}^{-1}$ & $\%$ & $\mathrm{~mm} \mathrm{~h}^{-1}$ & $\%$ & $\mathrm{~mm} \mathrm{~h}^{-1}$ & $\%$ & $\mathrm{~mm} \mathrm{~h}^{-1}$ & $\%$ \\
\hline 0.50 & 8.60 & 11.56 & 5.42 & 14.74 & 4.44 & 10.42 & 7.44 & 33.01 & 8.79 & 3.08 \\
\hline 1.00 & 7.55 & 6.16 & 4.69 & 4.44 & 4.77 & 8.74 & 6.68 & 20.87 & 8.04 & 9.76 \\
\hline 1.50 & 5.24 & 5.57 & 4.65 & 9.68 & 5.30 & 5.68 & 6.37 & 13.70 & 7.79 & 14.02 \\
\hline 2.00 & 4.34 & 7.77 & 5.45 & 15.39 & 6.69 & 10.73 & 7.47 & 8.24 & 9.01 & 10.98 \\
\hline 2.50 & 5.40 & 4.93 & 7.56 & 14.23 & 9.00 & 7.46 & 9.51 & 5.63 & 11.57 & 1.78 \\
\hline 3.00 & 8.37 & 8.13 & 10.54 & 13.72 & 12.11 & 6.69 & 12.59 & 4.12 & 15.16 & 4.26 \\
\hline 3.50 & 13.36 & 11.93 & 14.75 & 10.29 & 16.09 & 4.75 & 16.03 & 2.63 & 20.15 & 4.97 \\
\hline 4.00 & 20.26 & 3.33 & 17.70 & 8.38 & 19.98 & 0.81 & 19.20 & 2.57 & 24.27 & 5.75 \\
\hline 4.50 & 19.05 & 3.57 & 18.52 & 6.48 & 21.99 & 0.63 & 21.53 & 3.22 & 27.67 & 10.49 \\
\hline 5.00 & 23.67 & 5.51 & 19.58 & 9.13 & 23.68 & 4.40 & 24.24 & 3.44 & 30.22 & 9.36 \\
\hline 5.50 & 18.42 & 12.18 & 15.73 & 15.27 & 21.20 & 1.75 & 23.38 & 7.13 & 30.45 & 2.53 \\
\hline 6.00 & 18.27 & 1.65 & 14.12 & 11.13 & 17.96 & 2.06 & 21.93 & 8.08 & 29.79 & 6.54 \\
\hline 6.50 & 7.51 & 15.47 & 15.08 & 6.75 & 16.23 & 0.71 & 18.98 & 4.14 & 28.52 & 13.71 \\
\hline 7.00 & 2.06 & 38.09 & 12.67 & 16.00 & 11.97 & 1.35 & 16.13 & 1.83 & 21.88 & 17.03 \\
\hline 7.50 & 0.03 & 144.34 & 9.15 & 28.13 & 10.58 & 6.35 & 15.65 & 2.61 & 18.72 & 16.85 \\
\hline 8.00 & - & - & 3.33 & 31.14 & 6.92 & 0.33 & 11.02 & 14.86 & 11.83 & 18.90 \\
\hline 8.50 & - & - & 0.46 & 20.00 & 3.94 & 11.76 & 8.24 & 10.71 & 7.48 & 23.62 \\
\hline 9.00 & - & - & - & - & 1.23 & 20.75 & 3.23 & 14.69 & 3.45 & 18.19 \\
\hline 9.50 & - & - & - & - & 0.79 & 23.17 & 1.48 & 24.07 & 1.55 & 16.48 \\
\hline 10.00 & - & - & - & - & 0.12 & 100.00 & 0.23 & 100.00 & 0.64 & 124.08 \\
\hline 10.50 & - & - & - & - & - & - & - & - & 0.15 & 208.17 \\
\hline
\end{tabular}

discussed previously (Table 4). However, the norms for testing of rotary deflectors recommends the utilization of a single line of precipitation collectors. In this study, the flow rate sprinkler was evaluated using four lines and tests were performed in the field, where the potential for variability in data is greater. The fitted polynomial regressions for calculation of the maximal reach was performed using the same criteria as discussed previously. 
Table 4 - Average precipitation intensities (PI) and their respective coefficients of variation (CV) for the flows tested in the field using the six jet red rotary deflector.

\begin{tabular}{|c|c|c|c|c|c|c|c|c|c|c|}
\hline \multicolumn{11}{|c|}{ six jets } \\
\hline$\underset{\mathrm{kPa}}{\mathrm{H}}$ & \multicolumn{2}{|c|}{70} & \multicolumn{2}{|c|}{105} & \multicolumn{2}{|c|}{140} & \multicolumn{2}{|c|}{210} & \multicolumn{2}{|c|}{280} \\
\hline $\begin{array}{c}q_{\text {obs }} \\
\mathrm{dm}^{3} \mathrm{~s}^{-1}\end{array}$ & \multicolumn{2}{|c|}{0.575} & \multicolumn{2}{|c|}{0.7055} & \multicolumn{2}{|c|}{0.9722} & \multicolumn{2}{|c|}{1.1667} & \multicolumn{2}{|c|}{1.3888} \\
\hline Distance & $\mathrm{Pl}$ & $\mathrm{CV}$ & $\mathrm{PI}$ & CV & $\mathrm{PI}$ & $\mathrm{CV}$ & $\mathrm{Pl}$ & CV & $\mathrm{PI}$ & CV \\
\hline $\mathrm{m}$ & $\mathrm{mm} \mathrm{h}^{-1}$ & $\%$ & $\mathrm{~mm} \mathrm{~h}^{-1}$ & $\%$ & $\mathrm{~mm} \mathrm{~h}^{-1}$ & $\%$ & $\mathrm{~mm} \mathrm{~h}^{-1}$ & $\%$ & $\mathrm{~mm} \mathrm{~h}^{-1}$ & $\%$ \\
\hline 0.50 & 5.53 & 5.44 & 6.99 & 23.23 & 8.73 & 7.96 & 10.09 & 2.75 & 10.36 & 6.09 \\
\hline 1.00 & 6.78 & 1.71 & 8.70 & 14.17 & 10.52 & 7.89 & 12.59 & 0.74 & 12.40 & 0.92 \\
\hline 1.50 & 9.10 & 3.82 & 11.20 & 12.34 & 13.21 & 6.11 & 16.09 & 0.72 & 15.13 & 6.38 \\
\hline 2.00 & 14.24 & 0.81 & 17.59 & 20.76 & 19.97 & 5.93 & 23.73 & 0.10 & 23.04 & 5.20 \\
\hline 2.50 & 17.50 & 0.53 & 20.37 & 17.75 & 26.02 & 2.46 & 29.47 & 1.18 & 30.86 & 4.56 \\
\hline 3.00 & 21.20 & 0.44 & 22.13 & 16.33 & 29.10 & 3.35 & 32.18 & 1.73 & 36.60 & 1.97 \\
\hline 3.50 & 23.94 & 1.35 & 23.24 & 13.62 & 30.54 & 3.73 & 32.66 & 1.91 & 38.86 & 0.49 \\
\hline 4.00 & 20.69 & 1.12 & 21.76 & 3.25 & 30.57 & 1.01 & 32.48 & 3.64 & 38.41 & 0.67 \\
\hline 4.50 & 17.18 & 0.81 & 15.93 & 15.19 & 25.54 & 9.63 & 28.98 & 3.19 & 37.22 & 0.91 \\
\hline 5.00 & 17.82 & 5.46 & 14.81 & 24.36 & 21.23 & 9.16 & 26.27 & 0.79 & 37.31 & 2.11 \\
\hline 5.50 & 12.96 & 6.43 & 14.81 & 18.62 & 18.81 & 7.50 & 21.16 & 0.22 & 30.29 & 1.88 \\
\hline 6.00 & 8.19 & 5.09 & 13.70 & 20.36 & 18.64 & 5.99 & 19.07 & 0.00 & 24.84 & 1.58 \\
\hline 6.50 & 1.94 & 19.05 & 9.63 & 29.84 & 17.01 & 2.77 & 16.81 & 1.93 & 21.98 & 2.03 \\
\hline 7.00 & 0.19 & 50 & 4.03 & 30.85 & 10.57 & 12.88 & 10.76 & 6.67 & 14.29 & 3.27 \\
\hline 7.50 & - & - & 1.48 & 51.63 & 7.22 & 11.10 & 7.69 & 9.64 & 8.92 & 2.49 \\
\hline 8.00 & - & - & - & - & 3.30 & 28.16 & 3.80 & 12.20 & 3.08 & 8.98 \\
\hline 8.50 & - & - & - & - & 1.20 & 38.46 & 1.69 & 20.55 & 0.97 & 33.27 \\
\hline 9.00 & - & - & - & - & 0.19 & 168.20 & 0.63 & 48.15 & - & - \\
\hline 9.50 & - & - & - & - & - & - & 0.12 & 100.00 & - & - \\
\hline
\end{tabular}
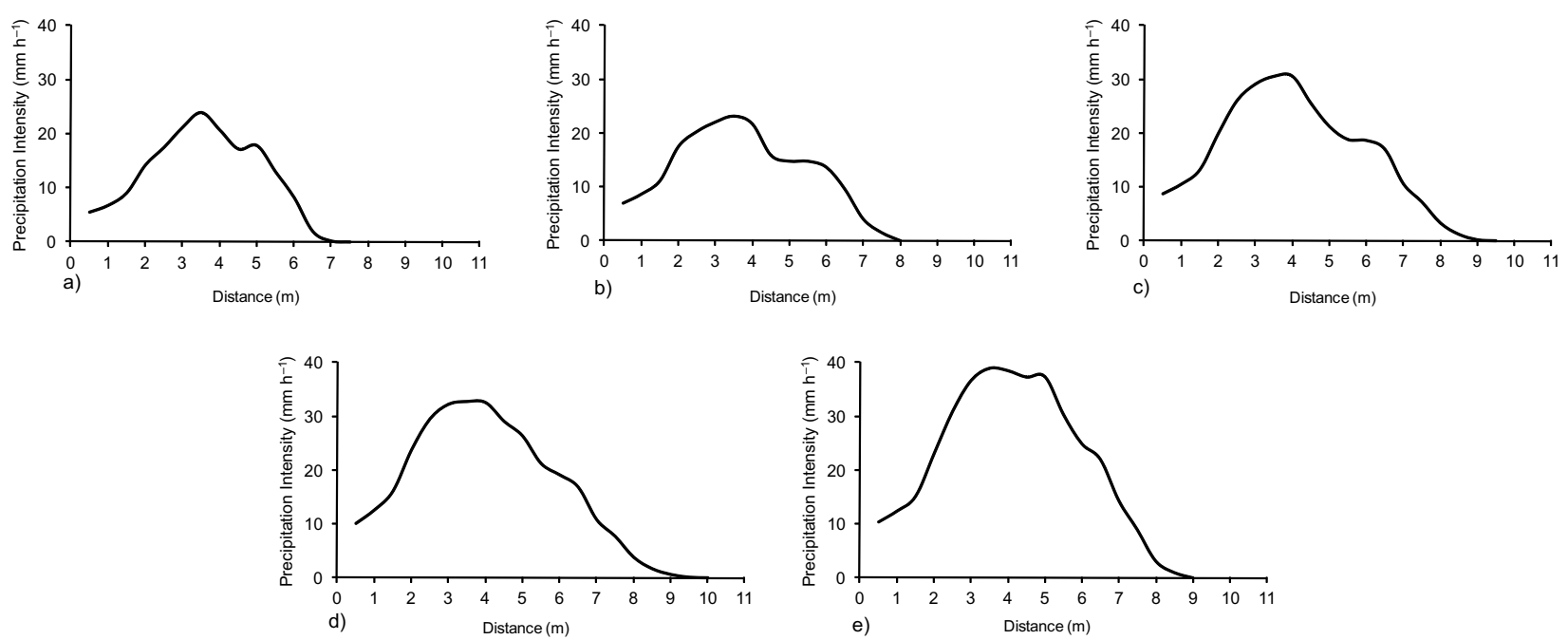

Figure 5 - Average distribution profiles of the variable rate sprinkler operating with different pressures and flow rates and with six jet red rotary reflector. a) $\mathrm{q}=0.575 \mathrm{dm}^{3} \mathrm{~s}^{-1}, \mathrm{H}=70 \mathrm{kPa}$; b) $\mathrm{q}=0.7055 \mathrm{dm}^{3} \mathrm{~s}^{-1}, \mathrm{H}=105 \mathrm{kPa}$; c) q=0.9722 $\mathrm{dm}^{3} \mathrm{~s}^{-1}, \mathrm{H}=140 \mathrm{kPa}$; d) $\mathrm{q}=1.1667 \mathrm{dm}$ $\mathrm{s}^{-1}, \mathrm{H}=210 \mathrm{kPa}$; e) $\mathrm{q}=1.3889 \mathrm{~m}^{3} \mathrm{~s}^{-1}, \mathrm{H}=200 \mathrm{kPa}$.

The variability encountered in the experiments may be explained due to the home-made construction of the deflector support. In the first tests the support was constructed of PVC, which for high flow rates presented intense vibration which influenced dispersion. When using the second support (Figure 3b), constructed of PVC along with two metal pins, similar results were encountered. In the third and last support, constructed of PVC 
Table 5 - Maximum throw determined by the average distribution profile referring to the operating conditions of the variable rate sprinkler (VRS).

\begin{tabular}{|c|c|c|c|c|c|c|c|c|c|c|}
\hline \multirow{2}{*}{$\mathrm{H}$} & \multirow{2}{*}{ № of jets } & \multirow{2}{*}{$\phi$} & \multirow{2}{*}{$h_{2}$} & \multirow{2}{*}{$q_{\text {est }}$} & \multirow{2}{*}{$q_{o b s}$} & \multicolumn{2}{|c|}{ Wind } & \multirow{2}{*}{$\begin{array}{l}\text { Rotation of } \\
\text { the deflector }\end{array}$} & \multirow{2}{*}{ Date } & \multirow{2}{*}{ Throw } \\
\hline & & & & & & v & Direction & & & \\
\hline $\mathrm{kPa}$ & & degrees & $\mathrm{mm}$ & \multicolumn{2}{|c|}{$-\mathrm{dm}^{3} \mathrm{~s}^{-1}-$} & $\mathrm{m} \mathrm{s}^{-1}$ & & $\mathrm{rpm}$ & & $\mathrm{m}$ \\
\hline 70 & 4 & 2880 & 7.60 & 0.6000 & 0.6166 & 0.012 & $32^{\circ} \mathrm{N}$ & 1.20 & May 13 & 7.30 \\
\hline 105 & 4 & 2520 & 6.65 & 0.6750 & 0.7083 & 0.098 & $27 \circ \mathrm{W}$ & 1.45 & May 16 & 8.54 \\
\hline 140 & 4 & 3600 & 9.50 & 0.9527 & 0.9722 & 0.088 & $18^{\circ} \mathrm{S}$ & 4.26 & May 18 & 9.79 \\
\hline 210 & 4 & 3240 & 8.55 & 1.1083 & 1.1667 & 0.125 & $18^{\circ} \mathrm{S}$ & 4.45 & May 20 & 10.30 \\
\hline 280 & 4 & 3960 & 10.45 & 1.3972 & 1.3889 & 0.100 & $22^{\circ} \mathrm{W}$ & 12.58 & May 28 & 10.35 \\
\hline 70 & 6 & 2700 & 7.13 & 0.5750 & 0.5750 & 0.384 & $2^{\circ} \mathrm{O}$ & 1.69 & May 23 & 7.53 \\
\hline 105 & 6 & 2520 & 6.65 & 0.6750 & 0.7055 & 0.301 & $27^{\circ} \mathrm{W}$ & 2.86 & May 17 & 7.82 \\
\hline 140 & 6 & 3600 & 9.50 & 0.9527 & 0.9722 & 0.089 & $16^{\circ} \mathrm{S}$ & 4.26 & May 18 & 8.91 \\
\hline 210 & 6 & 3240 & 8.55 & 1.1083 & 1.1667 & 0.158 & $2^{\circ} 0$ & 7.31 & May 21 & 10.38 \\
\hline 280 & 6 & 3960 & 10.45 & 1.3972 & 1.3889 & 0.050 & $27 \circ \mathrm{W}$ & 12.60 & May 29 & 8.61 \\
\hline
\end{tabular}
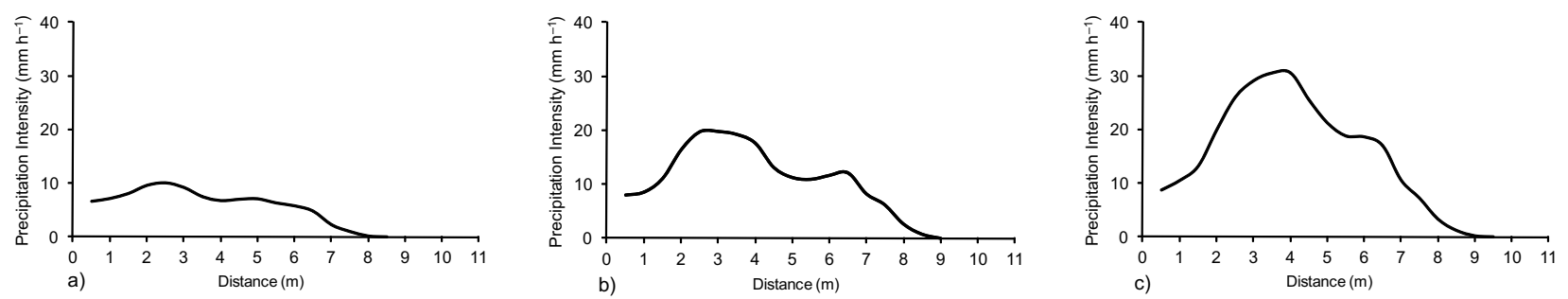

Figure 6 - Distribution profiles of the variable rate sprinkler operating at the same pressure with different flow rates as a function of pin movement in $140 \mathrm{kPa}$. a) $\mathrm{q}=0.2777 \mathrm{dm}^{3} \mathrm{~s}^{-1}$; b) $\mathrm{q}=0.6388 \mathrm{dm}^{3} \mathrm{~s}^{-1}$; c) $\mathrm{q}=0.97222 \mathrm{dm}^{3} \mathrm{~s}^{-1}$.

and four metal pins (Figure 3a), the improved construction allowed for greater stability and consequently less dispersion of the values.

Alterations were made in distance between the center of the deflector and exit of the water jet in an attempt to achieve better results, as well as in the inclination of the deflector which also contributed to variations in the results. It is believed that during utilization of industrial sprinklers in subsequent works based on the prototype tested here, there will be less variability in results. Cost of the tested sprinkler is linked to utilization of a stepper motor for each sprinkler. The variable rate sprinkler of King and Kincaid (2004) utilized the pulsing technique and a solenoid valve for each sprinkler. Solenoid valves present a lower fixed cost compared to stepper motors of the same size. On the other hand, the stepper motor presents a longer useful life and lower energy consumption since it is not actuated during the entire irritation period as in the case of solenoids, thus reducing the total cost of the system over time. Furthermore, with the stepper motor it was possible to achieve much more precise flow rates, as presented by Armindo et al. (2010). However, it is also expected that in mass production the unitary price will be more accessible to the customer. Based on the adjusted polynomials, the maximum throw of each condition was therefore determined (Table 5).

In general, the VRS with the four jet deflector (green) resulted in greater water application throw compared to the six jet deflector (red). However, the six jet deflector showed greater precipitation intensities, as well as better distribution. Thus, the selection of the deflector to be utilized should be based on project requirements, respecting the difference in the obtained results. The variance present between the four profiles, referring to the four lines of collectors, can be explained by factors such as: influence of wind velocity and direction, eccentricity between the water stream and the center of the deflector, eccentricity caused by the pin, small misalignments of the deflector in relation to the reference plane, small vibrations of the deflector support, small changes in terrain level, among others.

Performance of the VRS was also analyzed when operating at low, medium and high flow rates at a pressure of $140 \mathrm{kPa}$, obtaining average distribution profiles (Figure 6). Maximum throw was determined referring to each profile based on the same criteria discussed previously (Table 6). For flow rates of 0.2777 to $0.9722 \mathrm{dm}^{3}$ $\mathrm{s}^{-1}$, at the same pressure, the VRS prototype presented stable distribution profiles, confirming its operational potential without compromising water application efficiency. In this case, there appears to be no difference between the throws observed for the flows of 0.6388 and $0.9722 \mathrm{dm}^{3} \mathrm{~s}^{-1}$, where the last resulted in better precipitation intensity, which can result in shorter irrigation times.

According to the technical norms followed in these experimental tests, it is acceptable to use only one line of collectors to test sprinklers with rotary deflectors. However, because the utilize sprinkler was treated as a pro- 

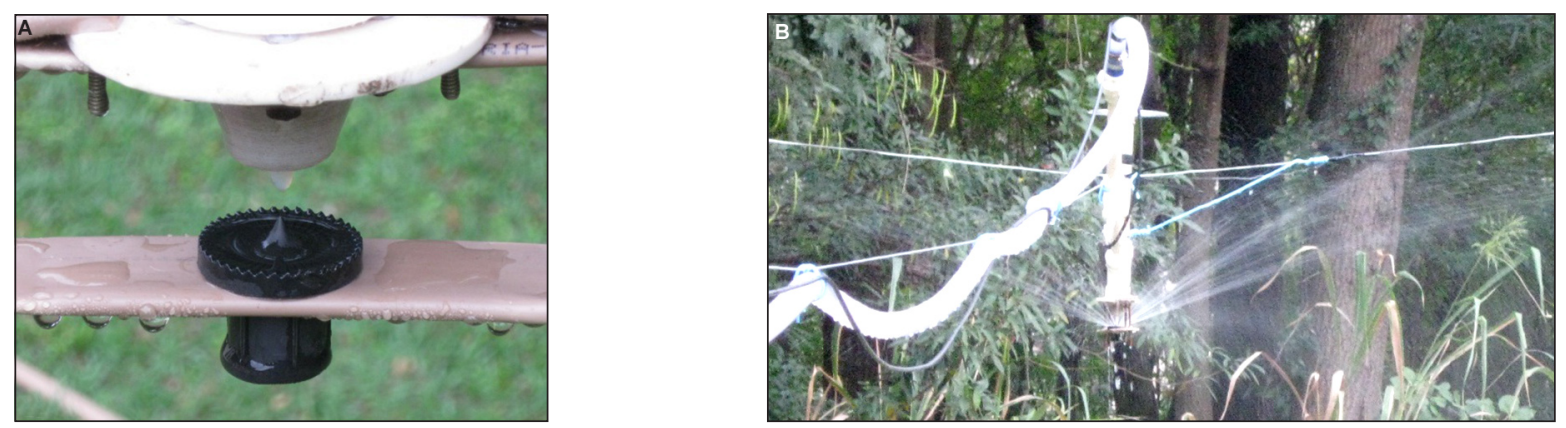

Figure 7 - Variable rate sprinkler operating in spraying conditions with smaller water droplets. A) utilized fixed deflector. B) visual aspect of the spray.

Table 6 - Values of throw obtained for the different flow rates at the same pressure for the six jet deflector.

\begin{tabular}{|c|c|c|c|c|c|c|c|c|c|c|}
\hline \multirow{2}{*}{ H } & \multirow{2}{*}{ № of jets } & \multirow{2}{*}{$\varphi$} & \multirow{2}{*}{$\mathrm{h}_{2}$} & \multirow{2}{*}{$q_{\text {est }}$} & \multirow{2}{*}{$q_{o b s}$} & \multicolumn{2}{|c|}{ Wind } & \multirow{2}{*}{$\begin{array}{l}\text { Rotation } \\
\text { of the deflector }\end{array}$} & \multirow{2}{*}{ Date } & \multirow{2}{*}{ Throw } \\
\hline & & & & & & $\mathrm{v}$ & Direction & & & \\
\hline $\mathrm{kPa}$ & & degrees & m & - & $\longrightarrow$ & $\mathrm{m} \mathrm{s}^{-1}$ & & $\mathrm{rpm}$ & & $\mathrm{m}$ \\
\hline 140 & 4 & 720 & 1.90 & 0.2750 & 0.2750 & 0.317 & $16^{\circ} \mathrm{S}$ & 0.40 & May 25 & 7.96 \\
\hline 140 & 4 & 1800 & 4.75 & 0.6111 & 0.6416 & 0.024 & $32^{\circ} \mathrm{N}$ & 2.01 & May 24 & 8.69 \\
\hline 140 & 4 & 3600 & 9.50 & 0.9527 & 0.9722 & 0.089 & $16^{\circ} \mathrm{S}$ & 4.26 & May 18 & 8.91 \\
\hline
\end{tabular}

totype, it was opted to work with four lines of collectors and utilized the average of the four; it is therefore emphasized that for each line there were three repetitions, meaning each average profile was the result of an average of twelve observations. Moreover, data was collected on dates in which wind velocity did not exceed $1.3 \mathrm{~m} \mathrm{~s}^{-1}$, as suggested by the technical norms.

Averages of replications which present conditions without wind or with winds less than $1.3 \mathrm{~m} \mathrm{~s}^{-1}$ were performed, outside of these experimental control conditions interference may be observed among treatments. Moreover, the utilized wind gauge informed the total distance traveled due to effect of the wind during the entire experimental time of $1 \mathrm{~h}$. It was not possible to determine wind gusts and during the majority of the experimental period there was no wind, but at short instances there were surely winds with velocities greater than $1.3 \mathrm{~m} \mathrm{~s}^{-1}$ which were not recorded and likely interfered on the experiment. Another important factor was the direction of winds which sometimes changed during the experimental period, affecting the results. In future field studies the use of wind gauges integrated with a data logger is recommended in order to obtain graphs which present the behavior of wind conditions during the test periods or at lease simple use of a wind gauge.

Eccentricity between the water jet and the center of the deflector is another characteristic which needs to be perfected in future variable rate sprinklers. For small nozzle openings, direction of the water jet changes in function of the rotation of the pin causing the water stream to strike points off-center which causes completely non-uniform distribution profiles. To correct this problem it is necessary to align the center of the reflector to the outlet of the water stream in each flow rate to be tested in the field. This problem is believed to be a fault of precision in alignment of the pin, encountered in the construction of the prototype, which would not occur in the construction of a commercial variable rate sprinkler.

The support constructed to serve as a base to the tested deflectors suffered deformation during the field tests, being another important factor which effected repeatability of the data. When subjected to low flow rates, the first support utilized operated stably, but forceful vibrations were observed when the pressure was increased, which interfered on the distribution profile. To eliminate this effect, it was necessary to use other supports which provided greater resistance to vibration.

When working with four lines of precipitation collectors and adopting a spacing of $0.5 \mathrm{~m}$, a small difference was observed between the maximal throws of each line. In determined experimental flow rates, the water stream reached the opening of the last collector in one line and only the stake of the last collector in another line bringing about the mentioned difference. A small imbalance of the deflector, a small eccentricity in the outlet of the water stream or even a small difference in terrain height and thus height of the collectors are factors which cause this difference in profiles.

When operating the VRS with a fixed deflector at pressure of $280 \mathrm{kPa}$ and a small nozzle opening referring to a $90^{\circ}$ rotation of the pin, a flow of approximately $0.05222 \mathrm{dm}^{3} \mathrm{~s}^{-1}$ was observed which emits what appears to be a spray (Figure 7). Future tests with adhesive papers which assist in determination of volume mean diameter (VMD) and numeric mean diameter (NMD), as well as for determination of the application profile of the VRS operating under these conditions must be performed to prove this additional characteristic of the variable rate 
sprinkler which guarantees even greater versatility. If confirmed, the same equipment used for conventional irritation can also be used for precision irrigation and chemigation.

\section{Conclusion}

The technical feasibility of the variable rate sprinkler prototype was verified. With its use, linear and center pivot irrigation systems can be used in precision irrigation, varying the flow through the lateral pipe, with defined radial application profiles. Furthermore, in conventional irrigation, center pivots no longer need to present a model with multiple spray nozzles along the lateral line. Now, a single nozzle size can be used along the entire pipe length, obtaining the required flow at any point by movement of the pin that can even be performed manually. Under conditions of small nozzle opening with a fixed deflector and high operational pressure, the VRS produced visually small water droplets, and may possibly be used for foliar chemigation. An algorithm was successfully programmed for control of the stepper motor which presented excellent results for comparison between the estimated and observed flow rates.

\section{Acknowledgements}

To the following Brazilian Institutions for their financial support: Ministério da Ciência e Tecnologia (MCT), Conselho Nacional de Desenvolvimento Cientí- fico e Tecnológico (CNPq), Fundação de Amparo à Pesquisa do Estado de São Paulo (FAPESP) and Instituto Nacional de Ciência e Tecnologia em Engenharia de Irrigação (INCTEI).

\section{References}

Al-kufaishi, S.A.; Blackmore, B.S.; Sourell, H. 2006. The feasibility of using variable rate water application under a central pivot irrigation system. Irrigation and Drainage Systems 20: 317-327.

Armindo, R.A.; Botrel, T.A.; Garzella, T.C. 2010. Flow rate sprinkler for site-specific irrigation. Irrigation Science. DOI 10.1007/ s00271-010-0231-7.

Dukes, M.D.; Perry, C. 2006. Uniformity testing of variable-rate center pivot irrigation control systems. Precision Agriculture 7: 205-218

King, B.A.; Kincaid, D.C. 2004. A variable flow rate sprinkler for site-specific irrigation management. Applied Engineering in Agriculture 20: 765-770.

King, B.A.; Wall, R.W.; Kincaid, D.C.; Westermann, D.T. 2005 Field Testing of a variable rate sprinkler and control system for site-specific water and nutrient application. Applied Engineering in Agriculture. 21: 847-853.

Stone, K.C.; Sadler, E.J.; Millen, J.A.; Evans, D.E.; Camp, C.R. 2006. Water flow rates from a site-specific irrigation system. Applied Engineering in Agriculture. 22: 73-78.

Young, J.H.; Khalilian, A.; Owino, T.O.; Farahani, H.J.; Moore, S. 2009. Development of Clemson variable-rate lateral irrigation system. Computers and Electronics in Agriculture 68: 108-113. 